\title{
Deformation Behavior of a VT18U Titanium Alloy in the Oxidized State
}

\author{
M. S. Kalienko ${ }^{a, b}$, *, M. O. Leder ${ }^{a}$, A. V. Volkov ${ }^{a}$, A. V. Zhelnina ${ }^{a}$, and P. E. Panfilov ${ }^{b}$ \\ ${ }^{a}$ PSC VSMPO-AVISMA Corporation, Verkhnyaya Salda, 624760 Russia \\ ${ }^{b}$ Ural Federal University, Ekaterinburg, 620002 Russia \\ *e-mail:kamak@yandex.ru
}

Received May 8, 2019; revised May 14, 2019; accepted May 16, 2019

\begin{abstract}
The influence of the isothermal annealing conditions in air (at 560 and $625^{\circ} \mathrm{C}$ for $1000 \mathrm{~h}$ ) on the deformation behavior of a high-temperature VT18U titanium alloy under tension is studied. The plasticity of the alloy at room temperature decreases from 14 to $\approx 5 \%$ after annealing at the investigated temperatures. The thickness of the gas-saturated layer is 17 and $42 \mu \mathrm{m}$ after annealing at 560 and $625^{\circ} \mathrm{C}$, respectively. The main factor determining the plasticity of the alloy in the oxidized state is the oxygen content gradient in the gassaturated layer.
\end{abstract}

Keywords: titanium alloy, isothermal annealing, diffusion, lattice parameters, $\mathrm{X}$-ray diffraction analysis

DOI: $10.1134 / \mathrm{S} 0036029520040114$

\section{INTRODUCTION}

A VT18U alloy belongs to the pseudo- $\alpha$ class of titanium alloys, which have the highest high-temperature properties among the russian titanium alloys $[1,2]$. In the case of prolonged service, the maximum operating temperature of these alloys is restricted to $600^{\circ} \mathrm{C}$, since their high-temperature strength and creep strength decrease substantially at higher temperatures $[3,4]$. The service at a temperature higher than $400^{\circ} \mathrm{C}$ results in the formation of a gas-saturated layer, i.e., a solid soluiton of titanium strengthened with oxygen, on the surface of these alloys $[4,5]$. The strength of the layer is higher than that of the base metal, whereas the plasticity, the fracture toughness, and the fatigue fracture strength are low $[6,7]$. The presence of this layer is one of the causes of degradation of the tensile plasticity and the fatigue resistance of titanium alloys upon service at elevated temperatures [8-11]. Another factor of this change in the properties is the stability of the metallic matrix of the alloy, in which finely dispersed intermetallic phases can form due to phase transformations [12, 13].

The main parameters of the estimation of the heat resistance of titanium alloys are the thickness of the gas-saturated layer, the weight gain upon annealing, and the material parameters used for the description of oxygen diffusion during oxidation. The behavior during the oxidation of titanium alloys, which can be used at elevated temperatures, was described on the basis of the experimental data [14-17], and some models for the oxidation and prediction of the deformation behavior of these alloys were proposed.
The concentration of oxygen in the gas-saturated layer is the parameter determining the deformation behavior of titanium alloys in the oxidized state [18]. The purpose of this work is to study the thermal stability and the deformation behavior of a high-temperature VT18U titanium alloy after annealing at temperatures close to $600^{\circ} \mathrm{C}$.

\section{EXPERIMENTAL}

The samples cut from a 4-mm sheet of the VT18U titanium alloy (produced at PSC VSMPO-AVISMA Corporation) were studied. The alloy had the following chemical composition (wt \%): $6.5 \mathrm{Al}, 4.3 \mathrm{Zr}$, 2.4 Sn, 0.8 Nb, 0.7 Mo, 0.1 Si, and Ti for balance. The mechanical properties and the structure of the alloy were studied earlier [19]. The samples with a gage part $12.5 \times 50 \mathrm{~mm}$ in size according to standard ASTM E8 were used for studying the mechanical properties. The samples for tests were prepared on an electrospark discharge machine. After cutting, tensile samples were additionally etched to remove a melted side layer $0.02 \mathrm{~mm}$ thick. The samples $20 \times 20 \mathrm{~mm}$ in size were cut for X-ray diffraction studies (XRD). Prior to annealing, all samples were degreased with gasoline and cleaned with ethanol.

Isothermal annealing was carried out at 560 and $625^{\circ} \mathrm{C}$ for $1000 \mathrm{~h}$ in air (furnace with fan for blending air) with a temperature maintenance accuracy of $\pm 5^{\circ} \mathrm{C}$. After annealing, the gas-saturated layer was removed from some samples using grinding and etching. Tensile tests were carried out on a Zwick Z600 
Table 1. Mechanical properties of the VT18U alloy in various states

\begin{tabular}{l|c|c|c}
\hline \multicolumn{1}{c|}{ State } & $\sigma_{0,2}, \mathrm{MPa}$ & $\sigma_{\mathrm{u}}, \mathrm{MPa}$ & $\delta, \%$ \\
\hline $\begin{array}{l}\text { Initial } \\
\text { Annealing at } 560^{\circ} \mathrm{C},\end{array}$ & $1003 / 998$ & $1040 / 1037$ & $4.6 / 16.9$ \\
$1000 \mathrm{~h}$ & & & 14.2 \\
$\begin{array}{l}\text { Annealing at } 625^{\circ} \mathrm{C}, \\
1000 \mathrm{~h}\end{array}$ & $981 / 981$ & $1025 / 1031$ & $5.1 / 14.8$ \\
\hline
\end{tabular}

The results for the samples with the oxidized surface layer and after its removal are given before and after slash, respectively.

tensile testing machine at room temperature according to the ASTM E8 standard. The samples were tested in the oxidized state and with the removed gas-saturated layer (three samples in each state).

A fractographic study was conducted using a Leica MZ12.5 optical microscope and a Quanta 3D FEG scanning electron microscope. X-ray diffraction patterns were recorded radiation by Bruker D8 Advance diffractometer with a LynxEye detector under the following conditions: the tube voltage $40 \mathrm{kV}$, the tube current $40 \mathrm{~mA}$, the step was $0.02^{\circ}$, and the counting time per point was $0.5 \mathrm{~s}$. The lattice parameters were refined using the TOPAS 3 program by a full-profile analysis in the angular range $2 \theta=34^{\circ}-43^{\circ}$. The PDF2007 crystallographic database (EVA13.0.0.3 program) was used for qualitative phase analysis. The relative variations of the unit cell volume in the gassaturated layer were estimated as $\Delta V=\left(V_{\alpha}-V_{\alpha 0}\right) / V_{\alpha 0}$, where $V_{\alpha}$ denotes a unit cell volume of $\alpha$ phase near the oxide/metal interface after oxidation, and $V_{\alpha 0}$ its initial value.

Metallographic analysis was carried out and the Vickers hardness was measured (the load on the indenter was $98 \mathrm{mN}$ ) on microsections of the samples after they were studied by XRD on an Olympus GX71 optical microscope and a Shtruers Duramin hardness tester. The microsections were etched in a 5\% aqueous solution of hydrofluoric acid to estimate the gas-saturated layer thickness. The thickness of the structure near the surface with brighter contrast compared to the base metal was accepted to be the gas-saturated layer thickness. The obtained values were averaged over 60-70 measurements.

\section{RESULTS AND DISCUSSION}

According to the results of the tests, the relative elongation of the samples in the oxidized state after annealing at 560 and $625^{\circ} \mathrm{C}$ was 4.6 and $5.1 \%$, respectively (Table 1). The plasticity of the samples with the removed oxidized layer even somewhat increased, and the most noticeable increase was observed after annealing at $560^{\circ} \mathrm{C}$. This indicates a high thermal stability of the base metal and that the observed decrease in the plasticity is related to the surface gas-saturated layer.

The samples in the oxidized state decomposed without necking (Fig. 1); i.e., tensile deformation occurred due to uniform elongation of the gage portion of the sample. The oxide layer (oxide) exfoliated on the sample surface near the fracture surface, and the exfoliation was more pronounced for the sample annealed at $625^{\circ} \mathrm{C}$ (see Fig. 1b). The oxide layer on the alloy surface after annealing was shown by the arrow in Fig. 2a. Its thickness after annealing at 560 and $625^{\circ} \mathrm{C}$ was 280 and $941 \mathrm{~nm}$, respectively (Table 2). The thickness of the gas-saturated layer shown in Figs. 2a and 2d after annealing at $560^{\circ} \mathrm{C}$ was also substantially smaller: 17 vs. $42 \mu \mathrm{m}$ at $625^{\circ} \mathrm{C}$ (see Table 2).

Numerous periodical transverse cracks normal to the load direction are observed on the surface of the samples subjected to tensile fracture. The formation of similar cracks is also characteristic of other hotstrength alloys, for example, Ti6242S [9, 10, 16]. The formation of transverse cracks was found [15] to occur at the initial stage of plastic deformation in tensile tests. The larger the thickness of the gas-saturated
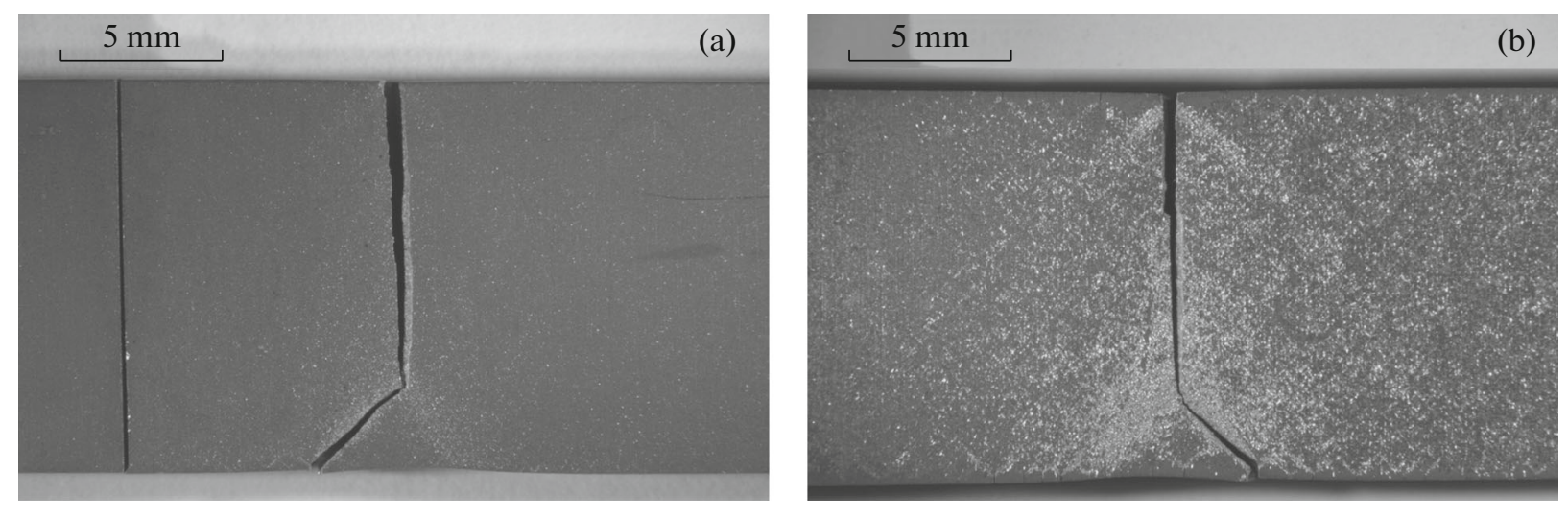

Fig. 1. VT18U alloy samples failed under tensile tests: preliminary annealing at (a) 560 and (b) $625^{\circ} \mathrm{C}$ for $1000 \mathrm{~h}$. 

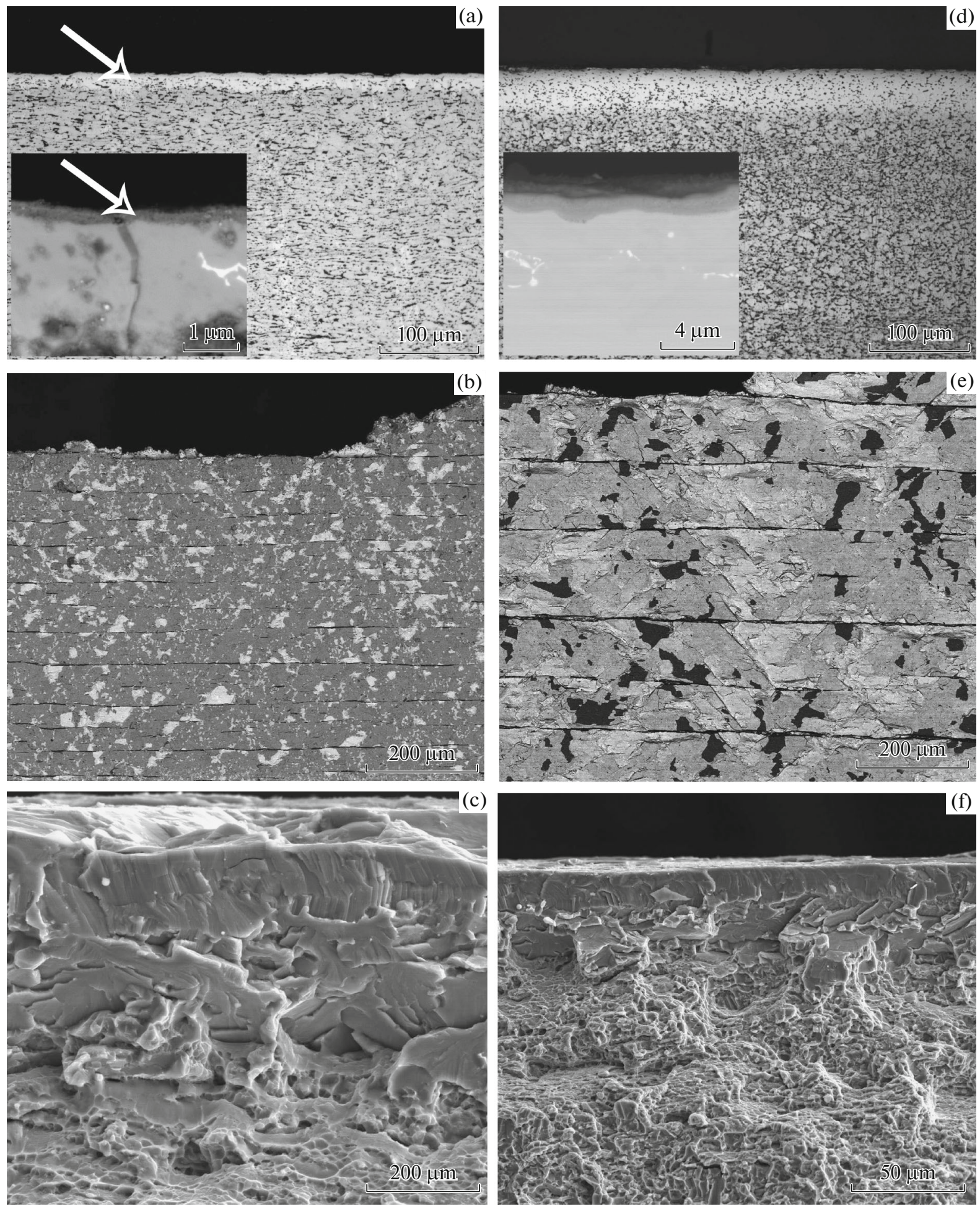

Fig. 2. Microstructure of the VT18U alloy after annealing at $(a-c) 560$ and $(d-f) 625^{\circ} \mathrm{C}$ : $(a, d)$ surface layer of the oxidized samples (cross section) (oxide layer is shown by arrow), (b, e) sample surface after tensile tests, and (c, f) micrographs of the fractured surface.

layer, the larger the distance between the cracks [15]. This is confirmed by the results obtained in the present work: after annealing at $560^{\circ} \mathrm{C}$ the distance between the cracks is $50 \mu \mathrm{m}$ on the average, and it is approxi- mately $120 \mu \mathrm{m}$ after annealing at $625^{\circ} \mathrm{C}$. Slip lines in the direction close to $45^{\circ}$ to the loading axis was observed near the sample surface after annealing at $625^{\circ} \mathrm{C}$ (Fig. 2e); i.e., the metal is formed between the 
Table 2. Thicknesses of the gas-saturated $\left(h_{\alpha}\right)$ and oxide $\left(h_{\text {ox }}\right)$ layers on the VT18U alloy surface after annealing in air and the lattice parameters of the $\alpha$ phase of the gas-saturated layer near the oxide/metal interface

\begin{tabular}{c|c|c|c|c}
\hline $\begin{array}{c}\text { Annealing } \\
\text { conditions }\end{array}$ & $h_{\alpha}, \mu \mathrm{m}$ & $h_{\mathrm{ox}}, \mathrm{nm}$ & $c / a$ & $\Delta V, \%$ \\
\hline $560^{\circ} \mathrm{C}, 1000 \mathrm{~h}$ & $17 \pm 2$ & $280 \pm 29$ & 1.615 & 4.14 \\
$625^{\circ} \mathrm{C}, 1000 \mathrm{~h}$ & $42 \pm 3$ & $941 \pm 100$ & 1.610 & 3.29 \\
\hline
\end{tabular}

transverse cracks via a shear mechanism, which could be a cause of oxide exfoliation (due to a higher plasticity) in these samples upon tension.

After tensile tests, a gas-saturated layer is present on the fracture surface of the samples by region with facets, unlike ductile dimple fracture of the base metal (Figs. 2c, 2f). The characteristic thickness of the surface gas-saturated layer on the fracture surfaces is comparable with the optical metallographic data.

The XRD patterns of the alloy samples in the oxidized state are presented in Fig. 3. The calculated depth of the penetration of the characteristic copper radiation ( $\lambda=1.5406 \AA$ ), which mainly contributes to the diffracted radiation, is about $3 \mu \mathrm{m}$ at the angle $2 \theta=43^{\circ}$ (Bruker AbsorbDX V1.1.4). The density of the oxide is lower than that of the metal; hence, $\mathrm{X}$-ray radiation partially passes through the oxide and the XRD patterns obtained make it possible to study the oxide and the metal near oxide/metal interface. The XRD patterns exhibit the diffraction lines of $\alpha-\mathrm{Ti}$ and the oxide based on rutile $\mathrm{TiO}_{2}$. The oxygen concentration in the gas-saturated layer adjacent to the oxide after annealing at $560^{\circ} \mathrm{C}$ is higher than that after annealing at $625^{\circ} \mathrm{C}$, and the increase in the unit cell volume of the $\alpha$ phase was 4.14 and $3.29 \%$, respectively. The ratio of the lattice parameters $c / a$ is also higher after annealing at $560^{\circ} \mathrm{C}$, since lattice parameter $c$ increases more rapidly than parameter $a$ with an increase in the oxygen concentration [7]. The

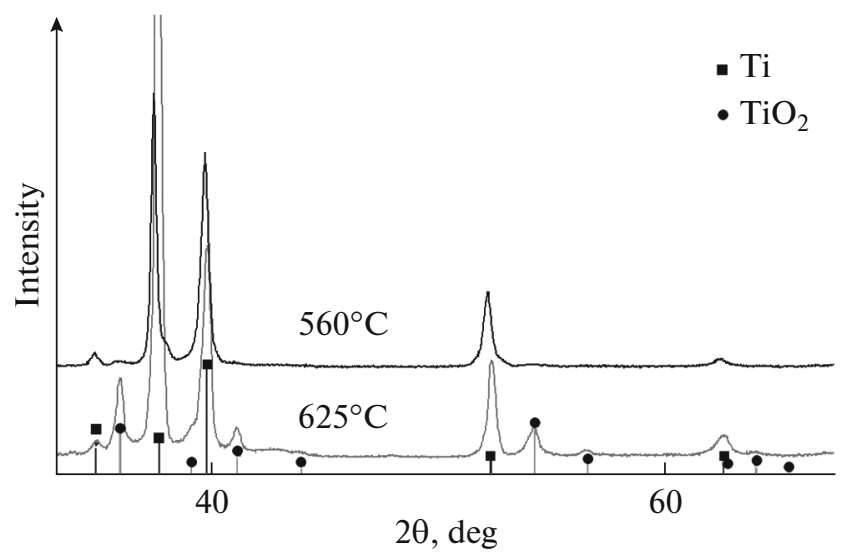

Fig. 3. XRD patterns of the VT18U alloy after annealing. obtained data are consistent with the results of hardness measurements in the gas-saturated layer (Fig. 4). The hardness profile shows an oxygen concentration gradient in the gas-saturated layer after alloy annealing at the temperatures under study.

The observed deformation behavior of the VT18U alloy cannot be attributed to such parameters as the gas-saturated layer thickness and the weight gain, which are commonly used for the evaluation of titanium alloy oxidation behavior of titanium alloy. The gas-saturated layer of the samples of the VT18U alloy after annealing at the higher temperature $\left(625^{\circ} \mathrm{C}\right)$ is twice as large as that after annealing at the lower temperature $\left(560^{\circ} \mathrm{C}\right)$. It seems reasonable to assume that tensile plasticity should be after annealing at $625^{\circ} \mathrm{C}$ than after $560^{\circ} \mathrm{C}$, but this is not true.

A comparison of several titanium alloys in the oxidized state after prolonged annealing at $560^{\circ} \mathrm{C}$ shows that the difference in the parameters of the oxide of these alloys is a cause, most likely, for the observed difference in the oxygen concentrations in metal near the oxide/metal interface [18]. The characteristics of the gas-saturated layers of the VT18U alloy found in this work are likely to be caused by other factors: the differences in the oxide growth rates, the oxygen diffusion rates through the oxide, and the oxygen diffusion rates into the base metal at the chosen temperatures. Additional precision studies are needed for exact establishment of the nature of the observed difference in the oxygen concentrations near the oxide/metal interface, since this process is studied insufficiently because of numerous factors affecting titanium oxidation. However, according to our primary estimation based on the constants obtained previously [20], the mechanism can be as follows. Although a thicker (by $\approx 3.3$ times) oxide layer is formed on the alloy surface at $625^{\circ} \mathrm{C}$ compared to that formed at $560^{\circ} \mathrm{C}$, the

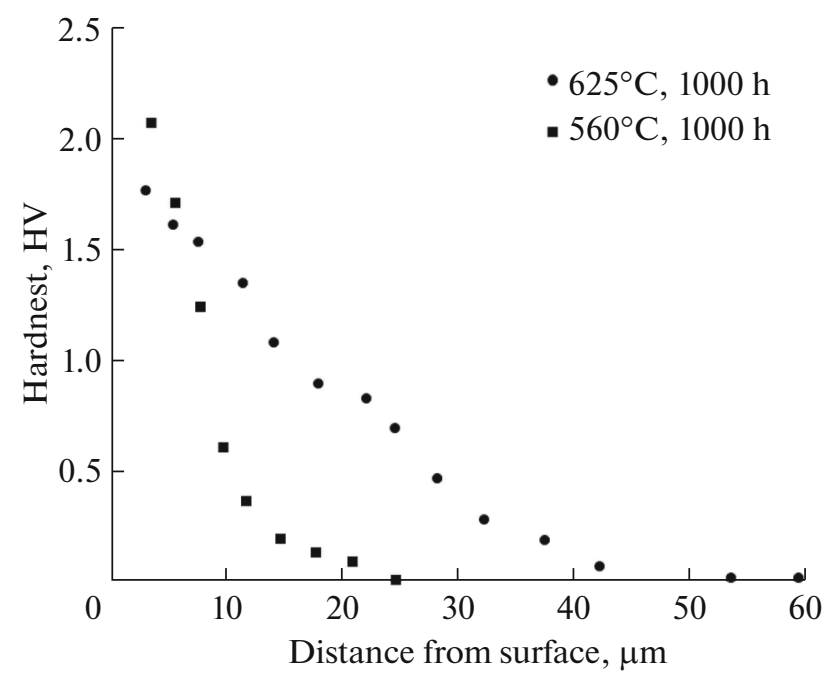

Fig. 4. Normalized hardness distribution in the gas-saturated layer of the VT18U alloy after annealing. 
oxygen income rate to the metal is higher than that at $560^{\circ} \mathrm{C}$ due to the difference in the oxygen diffusion rates through the oxide for these temperatures. The oxygen diffusion rate in the base metal at $560^{\circ} \mathrm{C}$ is lower than that at $625^{\circ} \mathrm{C}$, which results in the retention of a higher oxygen concentration gradient between the oxide/metal interface and the remote region of the gas-saturated layer adjacent to the base metal at $560^{\circ} \mathrm{C}$.

Thus, the deformation behavior of the VT18U alloy in the oxidized state is determined by the oxygen concentration in metal near the oxide/metal interface and the oxygen concentration gradient in the gas-saturated layer.

\section{CONCLUSIONS}

(1) The relative elongation of the VT18U alloy during tension after isothermal annealing at 560 and $625^{\circ} \mathrm{C}$ for $1000 \mathrm{~h}$ in air decreases more than by three times of initial because of gas-saturated layer formation.

(2) The gas-saturated layer thickness is 17 and $42 \mu \mathrm{m}$ and the oxide layer thickness is 280 and $941 \mathrm{~nm}$ after annealing at 560 and $625^{\circ} \mathrm{C}$, respectively.

(3) The unit cell volume of $\alpha$-Ti in the gas-saturated layer near the oxide/metal interface increased by 4.14 and $3.29 \%$ after annealing at 560 and $625^{\circ} \mathrm{C}$, respectively.

(4) The deformation behavior of the VT18U alloy samples in the oxidized state after prolonged isothermal annealing is related to different oxygen concentrations in metal near oxide/metal interface and different oxygen concentration gradients in the gas-saturated layer.

\section{REFERENCES}

1. O. P. Solonina and S. G. Glazunov, Titanium Alloys. High-Temperature Titanium Alloys (Metallurgiya, Moscow, 1976).

2. T. V. Pavlova, O. S. Kashapov, and N. A. Nochevnaya, "Titanium alloys for gas turbine engines," in All Materials. Encyclopedic Handbook (2012), Vol. 5, pp. 8-14.

3. B. A. Kolachev, I. S. Pol'kin, and V. D. Talalaev, Titanium Alloys in Various Countries (VILS, Moscow, 2000).

4. G. Lütjering and J. C. Williams, Titanium (Springer Science \& Business Media, Berlin, 2007).

5. N. M. Pul'tsin, Interaction of Titanium with Gases (Metallurgiya, Moscow, 1969).

6. Titanium and Titanium Alloys: Fundamentals and Applications, Ed. by C. Leyens and M. Peters (Wiley, Weinheim, 2003).

7. H. Conrad, "Effect of interstitial solutes on the strength and ductility of titanium," Prog. Mater. Sci. 26 (2-4), 123-403 (1981).
8. B. Geary, V. J. Bolam, S. L. Jenkins, and D. P. Davis, "High temperature titanium sheet for helicopter exhaust applications," in Proceedings of the 8th World Conference Titanium'95-Science and Technology (Institute of Materials, London, 1996), pp. 1638-1645.

9. A. L. Pilchak, W. J. Porter, and R. John, "Room temperature fracture processes of a near- $\alpha$ titanium alloy following elevated temperature exposure," J. Mater. Sci. 47, 7235-7253 (2012).

10. D. P. Satko, J. B. Shaffer, J. S. Tiley, S. L. Semiatin, and A. L. Pilchak, "Effect of microstructure on oxygen rich layer evolution and its impact on fatigue life during high-temperature application of $\alpha / \beta$ titanium," Acta Mater. 107, 377-389 (2016).

11. F. Sansoz, M. Almesallmy, and H. Ghonem, "Ductility exhaustion mechanisms in thermally exposed thin sheets of a near- $\beta$ titanium alloy," Met. Mater. Trans. A 35 (10), 3113-3127 (2004).

12. P. Davies, R. Pederson, M. Coleman, and S. Birosca, "The hierarchy of microstructure parameters affecting the tensile ductility in centrifugally cast and forged Ti834 alloy during high temperature exposure in air," Acta Mater. 117, 51-67 (2016).

13. A. A. Popov, M. O. Leder, M. A. Popova, N. G. Rossina, and I. V. Narygina, "Effect of alloying on precipitation of intermetallic phases in heat-resistant titanium alloys," Phys. Met. Metallogr. 116 (3), 261-266 (2015).

14. I. Gurrappa, "An oxidation model for predicting the life of titanium alloy components in gas turbine engines," J. Alloys Compd. 389 (1-2), 190-197 (2005).

15. T. A. Parthasathy, W. J. Porter, S. Boone, and R. John, "Life prediction under tension of titanium alloys that develop an oxygenated brittle case during use," Scr. Mater. 65 (5), 420-423 (2011).

16. J. Baillieux, C. Archambeau, and F. Emile, "Effect of the oxygen diffusion on the mechanical behavior of $\mathrm{Ti}-$ 6Al-2Sn-4Zr-2Mo-0.1Si alloy," in Proceedings of the 13th World Conference on Titanium (Wiley, Hoboken, 2016), pp. 1613-1618.

17. T. Kitashima and T. Kawamura, "Prediction of oxidation behavior of near- $\alpha$ titanium alloys," Scr. Mater. 124, 56-58 (2016).

18. M. S. Kalienko, A. V. Volkov, M. O. Leder, P. E. Panfilov, and A. V. Zhelnina, "Interstitial oxygen diffusion hardening-oxygen content and lattice parameters of titanium alloys," in Proceedings of the XVI International IUPAC Conference on High Temperature Materials Chemistry (Yekaterinburg, 2018), p. 248.

19. M. S. Kalienko, M. O. Leder, A. V. Volkov, A. V. Berestov, and A. V. Zhelnina, "Study of the mechanical properties and structure of sheets of the VT8, VT18U, and VT25U titanium alloys in the thermally strengthened state," Tekhn. Legkikh Splavov, No. 4, 37-41 (2017).

20. R. N. Shenoy, J. Unnam, and R. K. Clark, "Oxidation and embrittlement of $\mathrm{Ti}-6 \mathrm{Al}-2 \mathrm{Sn}-4 \mathrm{Zr}-2 \mathrm{Mo}$ alloy," Oxid. Met. 26 (1-2), 105-124 (1986).

Translated by E. Yablonskaya 